\title{
DIFFERENCES BETWEEN TWO JAPANESE HEALTH PROMOTION PROGRAMS ON MEASURES OF HEALTH AND WELLNESS.
}

Toshiaki Watanabe ${ }^{* 1}$, Koji Terasawa1 ${ }^{1}$, Keisuke Nakade², Yuki Murata1, CrossMark

Saiki Terasawa ${ }^{3}$, Kenich Nemoto4, Toshie Kobayashi5, Koki Nakajima4, Yong Zhang6, SuchindaJarupat Maruo7, Fumihito Sasamori $^{3}$, Naoko Hirota ${ }^{4}$, Masao Okuhara ${ }^{8}$

${ }^{* 1}$ Shinshu University, Faculty of Education, 6-Ro Nishinagano, Naganoshi, Nagano 380-8544,

2Minowa town Government Office, 10298 Nakaminowa, Minowamati, Kmiinagun, Nagano 399-4695, Japan

${ }^{3}$ Shinshu University Faculty of Electrical and Electronic Engineering, 4-17-1 Wakasato, Naganoshi, Nagano 380-0928, Japan

${ }^{4}$ Matsumoto University, 2095-1 Niimura, Matsumoto, 390-1241, Japan

${ }_{5}^{5}$ Department of Early Childhood Education, SeisenJogakuin College, 2-120-8 Ueno Nagano, 381-0085, Japan

${ }^{6}$ Nagano Prefecture College, 8-49-7, Miwa, Nagano, 380-0803, Japan

${ }^{7}$ School of Nursing, Ramathibodi Hospital, Faculty of Medicine, Mahidol University, Bangkok, Thailand

${ }^{8}$ Tokyo University of Science, Center of General Education and Humanities, 5000-1 Toyohira, Chino, Nagano 391-213, Japan

\section{ARTICLE INFO}

Corresponding Author:

Toshiaki Watanabe*

Shinshu University, Faculty of Education,

6-Ro Nishinagano, Naganoshi, Nagano

380-8544, Japan

toshiwa@shinshu-u.ac.jp

Key words: Anthropometry, Health Education, Health Promotion, Physical Fitness, Walking

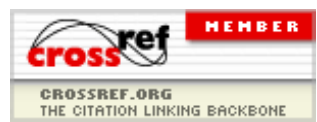

DOI:http://dx.doi.org/10.15520/ijm

hs.2015.vol5.iss4.75.170-181

\section{ABSTRACT}

We implemented and compared two 10-month health education programs in Minowa town and Matsumoto city, Nagano prefecture, Japan. The Matsumoto city cohort underwent a program of monthly classroom activities (CA group),whereas the Minowa town cohort were not only subjected to classroom activities but also performed 90-min strength and weight training once a week and were termed the classroom/training (CT) group.We measured anthropometric, blood pressure, physical fitness, blood chemistry, and brain function variables. All participants were provided pedometers and were encouraged to walk. Monthly seminars included education regarding yoga, exercise, blood pressure, nutrition, and other health-related topics. In total, 92 healthy participants were included in the CA group [age, $66.5 \pm 5.4$ years (mean \pm standard error of mean); 30males and62 females] and 46 healthy participants were included in the CT group (mean age $62.7 \pm 4.7$ years; 22 malesand 24 females).We observed significant differences between the average number of steps walked in the CA (7241.7 \pm 113.6$)$ and CT (8686.7 \pm 167.2$)$ groups. Both the groups both showed significant improvements in anthropometric, blood pressure, physical fitness, blood chemistry, and brain function tests; however, the CT group showed markedly greater improvement after the health education program than before participation. In conclusion, the CT programhad added benefits over the CA program because of the higher average amount of walking (approximately 1,400 steps) andthe inclusion of a weekly weight-training activity.

C2015, IJMHS, All Right Reserved 


\section{Watanbe et.al/Differences Between Two Japanese Health-Promotion Programs On Measures Of Health And Wellness}

Health promotion has received increased global attention since the World Health Organization (WHO) conference in Ottawa in 1986 [1] Based on this, Japan founded the "Kenko Nippon 21" national health campaign in 2000, which aimed to reduce mortality rates among late-middle-aged individuals, prolong health, improve quality of life, andpromote regional health. In 2002, the Japanese government required that each prefecturehad their own health-promotion policy [2].Subsequently, in 2013, the Japanese Ministry of Health, Labour andWelfare identified the need for a national policy to improve the prevention and treatment of metabolic syndrome, and for the performance of medical examinations. [3]. These health-promotion policies have led to a growth in the practice of health education at national, state, and city levels.

Globally, to fulfill the broad requirement to improve health, various health education programs have been devisedfocusing on the physical, mental, and social aspects of health. In addition, the WHO has published diagnostic criteria for the metabolic syndrome [4] andMora et al.have reported on the benefits of physical activityin its management[5].Moreover, scientific evidence confirms that physical activity, including simple walking exercises, can add years of active independent living, lower disability, and improve quality of life among the elderly [6]. Based on demonstrable health benefits, aerobics andstrength training are also recommended for the elderly $[5,7,8]$. This international research effort hasimproved the quality of information provided through health education, with a clear message that physical activity is beneficial.

In the context of this revolution in health promotion, we introduceddifferent health education programs in Matsumoto city andMinowa town (both in Nagano prefecture) in1997 and2004, respectively [9,10,11]. In 2005, Japan had the highest longevity in the world, and Nagano prefecture was among the areas with the greatest longevity. Our health education program comprises a series of monthly seminarsand energy expenditure measurements using a pedometer, with health assessments performed before and after the program. The aim of this study was to demonstrate that differences existed between the programs offered in Minowa town and Matsumoto city.

\section{METHOD}

\section{General method}

We implemented10-month health education programs from May 2011 to Feb 2012 in Minowa town and Matsumoto city, Nagano prefecture, Japan. The latest version, this program measuring energy expenditure using a pedometer and including anthropometric, blood pressure, physical fitness, blood chemistry, and brain function tests, was used. Participants were enrolled from the two health education programs. All participants were provided pedometers and encouraged to walk. They also participated in a series of monthly seminars regarding yoga, exercise, blood pressure, nutrition, and other health-related topics. However, the Matsumoto city cohort included only the monthly classroom activity,whereas the Minowa town cohort were subject to the classroom activity as well as a 90-min strength and weight training session once a week; these cohorts were termed the classroom activity (CA) group andclassroom/training (CT) group, respectively. Table I summarizes the contents of the programs. The study was approved by the Institutional Ethics Committee of Shinshu University, and it was conducted accordingto the latest guidelines of the Declaration of Helsinki. Written informed consent was obtained from all participants before inclusion.

Table I: Program contents of the 1-year health education in the CA and CT groups

\begin{tabular}{lll}
\hline Month & CA program & CT Program \\
\hline April & Opening ceremony & Opening ceremony \\
\hline May & Measurement before the health education and & Measurement before the health education, distribution of the pedometers, and \\
& distribution of the pedometers & training once a week \\
\hline June & Practical stretch and recreation & Lecture on the importance of health and training once a week \\
\hline July & Camp & Practical recreation and training once a week \\
\hline August & Exercise dance and PC Classroom & Hiking and training once a week \\
\hline September & Nature observation & Lecture of nutrition and training once a week \\
\hline October & Practical tennis and golf & Practical walking and training once a week \\
\hline
\end{tabular}


Watanbe et.al/Differences Between Two Japanese Health-Promotion Programs On Measures Of Health And Wellness

\begin{tabular}{lll}
\hline November & Craft making & Lecture on blood pressure and training once a week \\
\hline December & Tai Chi Chuan & Lecture on dental health and training once a week \\
\hline January & Aerobic exercises & Tai Chi Chuan and training once a week \\
\hline February & Measurement after completion of the program and & Measurement after completion of the program and collection of the pedometers \\
& collection of the pedometers & \\
\hline March & Closing ceremony & Closing ceremony \\
\hline
\end{tabular}

CA group: monthly classroom activity only, the Matsumoto city cohort; CT group: the classroom/training (CT) group, monthly classroom activity plus weekly 90-min strength and weight training, the Minowa town cohort

\section{Pedometers}

The number of steps walked and energy expenditure were measured in both the CA and CT groups. Exercise steps were defined as those taken during expenditure greater than 4 metabolic equivalents. The weight-bearing index (WBI) provided an easyassessment of the muscular strength of the lower limbs by evaluating the ability to stand up and by providing an approximate goal for the number of walking and exercise steps that were appropriate [13]. A pedometer model (Acos Inc., FS50) enabled data to be transferred and saved to a personal computer. Participants reported their results to a group leader atthe monthly meetings.

\section{Anthropometry and blood pressure}

Anthropometric measures included weight, height, body mass index (BMI), and waist circumference. Systolic and diastolic blood pressures were measured at rest, 15 min after arrival at a designated measurement location.

\section{Physical fitness test}

We used the physical fitness test approved by the Japan Ministry of Education, Culture, Sports, Science and Technology [14]. It comprised six physical assessments, including grip strength, sit-ups, sit-and-reach flexibility, eyes-open single-leg stance, 10-meter obstacle walk, and 6-min walk. Each participant's physical ability was assessed before and after the health education programs.

\section{Blood chemistry}

We assessed blood chemistry for the metabolic syndrome based on the recommendations of the Japanese Ministry of Health, Labour and Welfare [15]. Four components were measured as follows: high-density lipoprotein (HDL), low-density lipoprotein (LDL), triglyceride, and fasting glucose levels.Participants underwent blood chemistry testing before and after the health education programs.

\section{Go/no-go tasks for the assessment of brain function}

We adopted go/no-go tasks to assess brain function [16]. The go/no-go tasks comprised three experimental stages: formation, differentiation, and reverse differentiation. In the formation stage, participants were instructed to squeeze a rubber ball in response to a red light. During the differentiation stage, they squeezed the rubber ball in response to the red light but not a yellow light when red or yellow lights were displayed randomly. During the reverse differentiation stage, participants squeezed the rubber ball in response to the yellow light but not the red light. Participants completed 20 trials in each of the differentiation and reverse differentiation stages, with red and yellow lights displayed10 times each. In this study, incorrect responses were labeled as follows: we usedthe term "forget" to indicate that participants did not squeeze the ball when it was supposed to be squeezed and "mistake" to indicate that participants squeezed the ball when it was not supposed to be squeezed.

\section{Statistical analysis}

Paired t-testwas used to compare the results before and after participation in the health education programs. Factor analyses of the CA group versus theCT group were performed using a two-way repeated measure analysis of variance (ANOVA).Statistical Analyses were performed using SPSS for Windows, Version 11.0.1(SPSS Inc., Chicago, USA). The significance level was set at 0.05 . Data are presented as mean \pm standard error of mean (SE). 
Watanbe et.al/Differences Between Two Japanese Health-Promotion Programs On Measures Of Health And Wellness

Sample

The CA group included 92 healthy participantsaging $66.5 \pm 5.4$ (mean \pm SE) years, of which30 were males $(67.5 \pm 5.0$ years) and62 were females $(66.1 \pm$ 5.5years). The CT group included 46 healthy participants aging62.7 \pm 4.7 years, of which22 were males ( $64.9 \pm 4.7$ years) and 24 were females $(60.8 \pm$ 3.9years).

\section{Steps and exercise steps}

Significant differences were present in the average number of walking and exercise steps between the CA and CT groups. The CT group had a significantly higher averages compared with the CA group $(\mathrm{p}<0.001$; TableII).

Table II: Walking steps before and after the CT and CA health education programs

\begin{tabular}{lllll}
\hline Walking & Sex & CA & CT & p-value \\
\hline Walking/day (steps) & male and female & $7241.7 \pm 113.6$ & $8686.7 \pm 167.2$ & $<0.001$ \\
\hline & male & $8631.8 \pm 206.2$ & $10308.7 \pm 257.6$ & $<0.001$ \\
\hline Exercise Walking/day (steps) & male and female & $6500.6 \pm 114.1$ & $7323.8 \pm 175.7$ & $<0.001$ \\
\hline & male & $4638 \pm 98.0$ & $5523.2 \pm 149.4$ & $<0.001$ \\
\hline & female & $6061.0 \pm 199.4$ & $6948.8 \pm 240.5$ & $<0.01$ \\
\hline
\end{tabular}

Data are presented as mean \pm SE. CA group: monthly classroom activity only, the Matsumoto city cohort; CT group: the classroom/training (CT) group, monthly classroom activity plus weekly 90-min strength and weight training, the Minowa town cohort

The average number of walking and exercise stepsincreased from May to September among the males and females in the CA group. In May, walking and exercise steps accounted for $7597.0 \pm 331.0$ and $4604.9 \pm 299.5$ steps, respectively (males:9128.3 \pm 550.2 and $6179.8 \pm 562.6$,females:6784.5 \pm 367.7 and $3769.3 \pm 286.7$ ). In September, walking and exercise steps accounted for $8204.1 \pm 394.4$ and $5321.6 \pm 354.9$ steps, respectively (males: $10064.3 \pm 697.0$ and $6992.0 \pm 675.7$,females:7217.1 \pm 417.5 and $4435.3 \pm 351.8$ ). However, both walking and exercise steps decreased to $6760.3 \pm 379.2$ and $4986.4 \pm$ 409.1, respectively, by February (males: $8715.7 \pm 715.2$ and $6666.5 \pm 787.3$, females:5722.7 \pm 365.0 and $3971.2 \pm 373.0$; Figure 1).

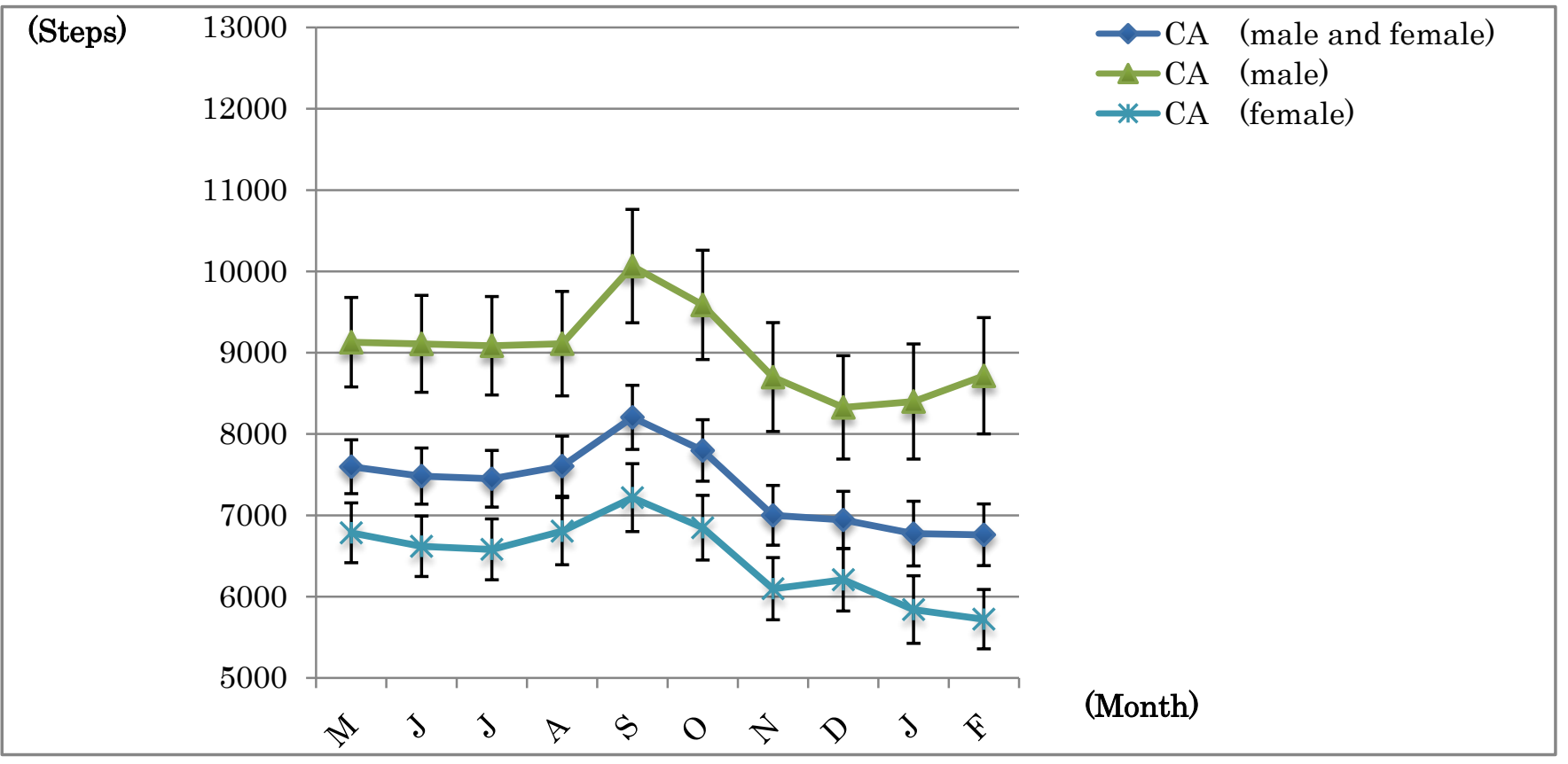

Figure 1: The number walking steps every month in the CA group.

CA group: monthly classroom activity only, the Matsumoto city cohort; CT group: the classroom/training (CT) group, monthly classroom activity plus weekly 90-min strength and weight training, the Minowa town cohort 
The average number of walking and exercise steps increased from May to October among the males and females in the CT group. In May, walking and exercise steps accounted for $7457.6 \pm 495.8$ and $4222.8 \pm 409.2$, respectively (males:8614.3 \pm 786.3 and5200.7 \pm 627.6 , females:6451.8 \pm 560.3 and3372.4 \pm 480.7 ). In October, walking and exercise steps accounted for $9382.6 \pm 512.6$ and $6235.2 \pm 468.0$, respectively (males:11307.5 \pm 799.3 and7736.5 \pm 768.4 , females:7957.5 \pm 496.6 and4984.0 \pm 441.2 ). However, both walking and exercise steps decreased to $7991.4 \pm 517.1$ and $5515.7 \pm$ 489.4, respectively, in February (males:9532.2 \pm 838.0 and7102.8 \pm 808.9, females:6707.4 \pm 524.7 and4193.0 \pm 450.7 ; Figure 2).

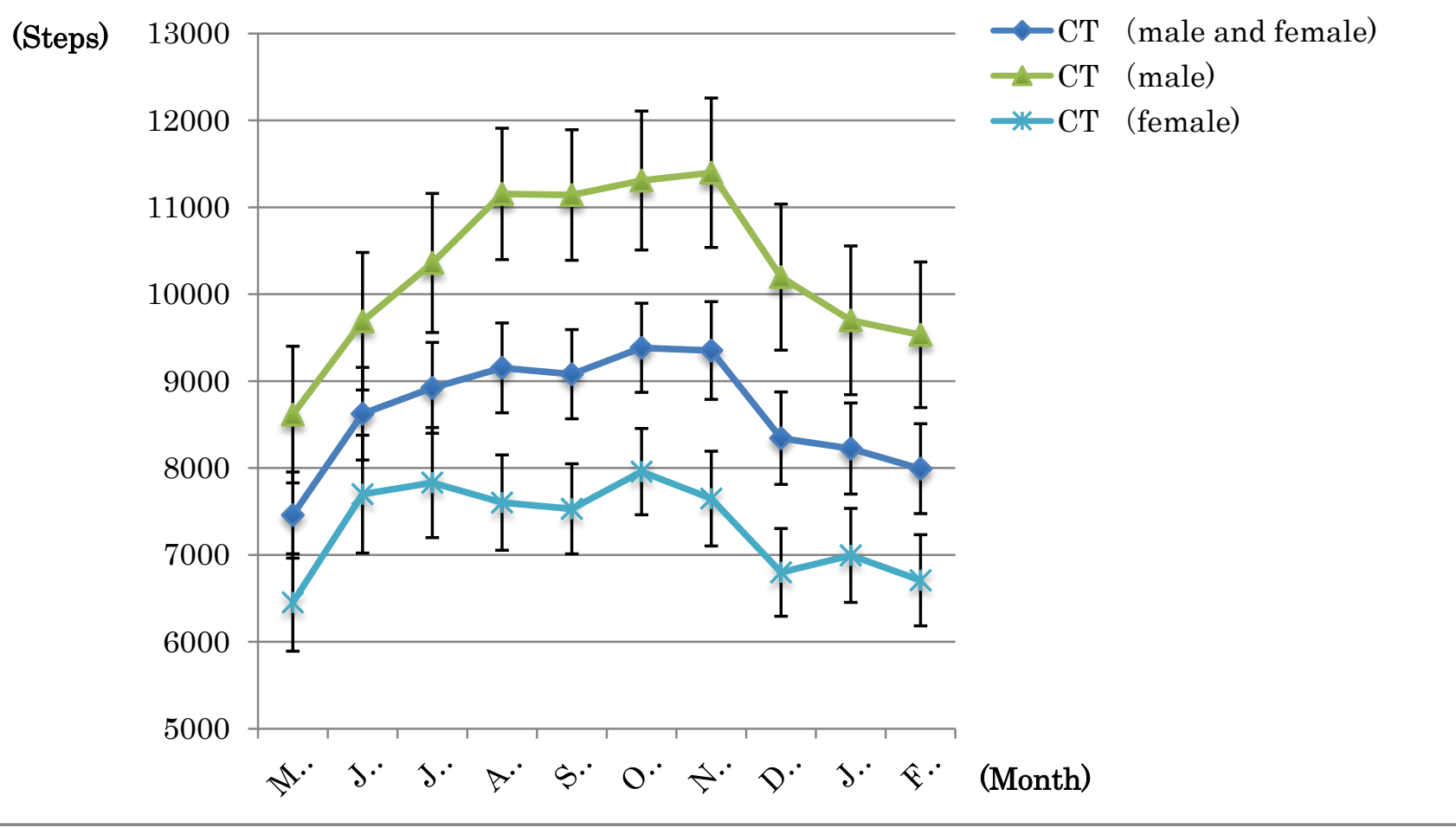

Figure 2: The number of walking steps by month in the CT group

CA group: monthly classroom activity only, the Matsumoto city cohort; CT group: the classroom/training (CT) group, monthly classroom activity plus weekly 90-min strength and weight training, the Minowa town cohort

\section{Anthropometry and blood pressure}

Table III summarizes the results of the anthropometric and blood pressure measurements. Before and after the health education programs, male and female in the CT group showed significant decreases in weight(overall $t=4.0$, malet $=3.0$, femalet $=2.8$ ) and waist circumference (overall $t=8.7$, male $t=$ 2.7,female $t=9.6$ ). The CT groupalso showed significant decreases in weight (overall $t=2.9$,female $t=4.5$ ), BMI (overall $t=3.0$,female $t=4.3$ ), waist circumference (overall $t=4.5$, male $t=2.2$,female $t=4.3$ ), systolic blood pressure (overall $t=4.5$, male $t=3.4$, femalet $=3.0$ ), and diastolic blood pressure (overall $\mathrm{t}=4.3$, male $\mathrm{t}=4.0$, femalet $=2.1$ ) from before to after the health education program.

Table III: Anthropometry before and after the CT and CA health education programs

\begin{tabular}{|c|c|c|c|c|c|c|c|}
\hline \multirow[b]{2}{*}{ Anthropometry } & \multirow[b]{2}{*}{ Sex } & \multicolumn{2}{|c|}{ CA } & \multicolumn{4}{|c|}{ CT } \\
\hline & & Before & After & p-value & Before & After & p-value \\
\hline \multirow[t]{3}{*}{ Weight (kg) } & male and female & $58.1 \pm 1.3$ & $57.2 \pm 1.3$ & $<0.001$ & $59.5 \pm 1.6$ & $58.5 \pm 1.6$ & $<0.01$ \\
\hline & male & $65.9 \pm 1.8$ & $64.7 \pm 1.8$ & $<0.01$ & $65.8 \pm 1.9$ & $65.1 \pm 1.7$ & NS \\
\hline & female & $54.3 \pm 1.4$ & $53.6 \pm 1.4$ & $<0.01$ & $54.5 \pm 2.0$ & $53.3 \pm 2.0$ & $<0.001$ \\
\hline \multirow[t]{3}{*}{ BMI (body mass index) } & male and female & $22.8 \pm 0.4$ & $22.8 \pm 0.4$ & NS & $23.0 \pm 0.5$ & $22.7 \pm 0.5$ & $<0.01$ \\
\hline & male & $24.2 \pm 0.6$ & $24.1 \pm 0.6$ & NS & $23.7 \pm 0.6$ & $23.5 \pm 0.5$ & NS \\
\hline & female & $22.2 \pm 0.4$ & $22.2 \pm 0.4$ & NS & $22.5 \pm 0.8$ & $22.0 \pm 0.9$ & $<0.001$ \\
\hline Waist circumference (cm) & male and female & $88.5 \pm 0.9$ & $83.9 \pm 1.0$ & $<0.001$ & $84.4 \pm 1.6$ & $82.2 \pm 1.5$ & $<0.001$ \\
\hline
\end{tabular}


Watanbe et.al/Differences Between Two Japanese Health-Promotion Programs On Measures Of Health And Wellness

\begin{tabular}{|c|c|c|c|c|c|c|c|}
\hline & male & $86.8 \pm 1.5$ & $85.1 \pm 1.7$ & $<0.05$ & $87.3 \pm 1.9$ & $85.5 \pm 1.4$ & $<0.05$ \\
\hline & female & $89.3 \pm 1.1$ & $83.3 \pm 1.3$ & $<0.001$ & $81.7 \pm 2.4$ & $79.3 \pm 2.3$ & $<0.001$ \\
\hline \multirow[t]{3}{*}{ Systolic blood pressure ( $\mathrm{mmHg}$ ) } & male and female & $132.2 \pm 1.8$ & $133.0 \pm 1.7$ & NS & $133.0 \pm 1.9$ & $125.5 \pm 2.0$ & $<0.001$ \\
\hline & male & $141.7 \pm 3.0$ & $139.2 \pm 3.1$ & NS & $141.2 \pm 2.3$ & $131.9 \pm 2.7$ & $<0.01$ \\
\hline & female & $128.0 \pm 2.0$ & $130.1 \pm 2.0$ & NS & $126.5 \pm 2.1$ & $120.5 \pm 2.6$ & $<0.01$ \\
\hline \multirow[t]{3}{*}{ Diastolic blood pressure (mmHg) } & male and female & $78.9 \pm 1.2$ & $81.1 \pm 1.2$ & NS & $80.4 \pm 1.2$ & $76.1 \pm 1.1$ & $<0.001$ \\
\hline & male & $84.5 \pm 2.4$ & $86.5 \pm 2.2$ & NS & $84.4 \pm 1.4$ & $77.9 \pm 1.9$ & $<0.001$ \\
\hline & female & $76.4 \pm 1.3$ & $78.8 \pm 1.4$ & NS & $77.2 \pm 1.5$ & $74.7 \pm 1.3$ & $<0.05$ \\
\hline
\end{tabular}

Data are presented as mean \pm SE. NS: not significant; BMI: body mass index; CA group: monthly classroom activity only, the Matsumoto city cohort; CT group: the classroom/training (CT) group, monthly classroom activity plus weekly 90 -min strength and weight training, the Minowa town cohort

\section{Physical Fitness test}

Table IV summarizes the results for the physical fitness tests. The CA groupshowed significant improvement in sit-ups (overall $t=-2.2$, male $t=-2.8$ ), sit-and-reach flexibility (overall $\mathrm{t}=-3.6$, femalet $=-3.4$ ), eyes-open single-leg stance (overall $\mathrm{t}=-2.2$ ), the 10 - $\mathrm{m}$ obstacle walk $($ overall $\mathrm{t}=9.9$, malet $=5.7$, female $t=8.0$ ), and the 6-min walk (overall $t=-7.6$, male $t=-7.3$, female $t=-5.0$ ) from before to after the health education program. The CT groupshowed significant improvement in handgrip strength (overall $t=-7.6$, male $t=-4.9$, femalet $=-5.7$ ), sit-ups (overall $t=-6.7$, male $t=-4.32$,female $t=-5.1$ ), sit-and-reach flexibility (overall $t=-8.8$, male $t=-6.4$,female $t=-6.0$ ), 10-m obstacle walk (overall $t=17.3$, male $t=12.4$,female $t=11.9$ ), and 6-min walk (overall $\mathrm{t}=-14.3$, male $\mathrm{t}=-14.1$,female $\mathrm{t}=-7.8$ ) from before to after the health education program.

Table IV: Physical fitness before and after the CT and CA health education programs

CA

CT

\begin{tabular}{|c|c|c|c|c|c|c|c|}
\hline Physical Fitness & Sex & Before & After & p-value & Before & After & p-value \\
\hline \multirow[t]{3}{*}{ Handgrip strength (kg) } & male and female & $28.3 \pm 1.0$ & $28.1 \pm 0.9$ & NS & $33.6 \pm 1.5$ & $37.3 \pm 1.5$ & $<0.001$ \\
\hline & male & $37.6 \pm 0.9$ & $37.1 \pm 0.8$ & NS & $41.6 \pm 1.4$ & $45.3 \pm 1.4$ & $<0.001$ \\
\hline & female & $24.1 \pm 0.6$ & $24.0 \pm 0.7$ & NS & $26.0 \pm 0.9$ & $29.8 \pm 1.0$ & $<0.001$ \\
\hline \multirow[t]{3}{*}{ Sit-up (reps) } & male and female & $13.0 \pm 0.6$ & $14.4 \pm 0.8$ & $<0.05$ & $11.9 \pm 0.9$ & $15.3 \pm 0.9$ & $<0.001$ \\
\hline & male & $14.7 \pm 1.2$ & $17.5 \pm 1.3$ & $<0.05$ & $13.6 \pm 1.0$ & $16.5 \pm 1.1$ & $<0.001$ \\
\hline & female & $12.2 \pm 0.7$ & $12.9 \pm 1.0$ & NS & $10.3 \pm 1.3$ & $14.1 \pm 1.4$ & $<0.001$ \\
\hline \multirow[t]{3}{*}{ Sit-and-reach flexibility $(\mathrm{cm})$} & male and female & $39.3 \pm 1.1$ & $42.5 \pm 1.2$ & $<0.001$ & $42.6 \pm 1.3$ & $47.4 \pm 1.1$ & $<0.001$ \\
\hline & male & $34.5 \pm 2.0$ & $37.2 \pm 2.3$ & NS & $39.6 \pm 2.3$ & $44.9 \pm 2.0$ & $<0.001$ \\
\hline & female & $41.5 \pm 1.2$ & $44.9 \pm 1.3$ & $<0.01$ & $45.4 \pm 1.1$ & $49.7 \pm 1.1$ & $<0.001$ \\
\hline \multirow[t]{3}{*}{ Eyes-open single-leg stance (s) } & male and female & $97.5 \pm 4.5$ & $105.1 \pm 3.7$ & $<0.05$ & $106.0 \pm 4.5$ & $105.7 \pm 4.5$ & NS \\
\hline & male & $94.8 \pm 8.3$ & $98.5 \pm 7.1$ & NS & $98.4 \pm 8.5$ & $97.0 \pm 8.4$ & NS \\
\hline & female & $98.8 \pm 5.4$ & $108.3 \pm 4.3$ & NS & $112.3 \pm 3.7$ & $112.9 \pm 4.0$ & NS \\
\hline \multirow[t]{3}{*}{ 10-m obstacle walk (s) } & male and female & $5.3 \pm 0.1$ & $4.5 \pm 0.1$ & $<0.001$ & $6.8 \pm 0.1$ & $5.1 \pm 0.1$ & $<0.001$ \\
\hline & male & $4.8 \pm 0.2$ & $3.9 \pm 0.1$ & $<0.001$ & $6.6 \pm 0.2$ & $5.0 \pm 0.2$ & $<0.001$ \\
\hline & female & $5.5 \pm 0.2$ & $4.7 \pm 0.2$ & $<0.001$ & $7.0 \pm 0.1$ & $5.2 \pm 0.2$ & $<0.001$ \\
\hline \multirow[t]{2}{*}{ 6-min walk (m) } & male and female & $638.9 \pm 8.8$ & $685.1 \pm 9.6$ & $<0.001$ & $622.2 \pm 7.3$ & $719.9 \pm 9.2$ & $<0.001$ \\
\hline & male & $652.2 \pm 17.0$ & $716.7 \pm 18.9$ & $<0.001$ & $633.3 \pm 11.0$ & $737.8 \pm 11.9$ & $<0.001$ \\
\hline
\end{tabular}


Watanbe et.al/Differences Between Two Japanese Health-Promotion Programs On Measures Of Health And Wellness

female

$632.9 \pm 10.2$

$670.9 \pm 10.5$

$<0.001$

$610.5 \pm 9.0$

$701.1 \pm 13.0$

$<0.001$

Data are presented as mean \pm SE. NS: not significant; CA group: monthly classroom activity only, the Matsumoto city cohort; CT group: the classroom/training (CT) group, monthly classroom activity plus weekly 90-min strength and weight training, the Minowa town cohort

\section{Blood chemistry}

Table V summarizes the results for the blood chemistry tests. The CA group showed no significant improvement in HDL, LDL, ortriglyceridelevels from before to after the health education program. However, fasting glucose (overall $t=-3.6$, male $t=-2.6$,female $t=-2.6$ ) and glycosylated hemoglobin $($ HbA1c;overall $t=-7.9$, malet $=-2.9$,female $t=-8.7)$ levels were significantly increased after the health education program. The CT groupalso showed no significant improvement in HDL, LDL, or triglyceride levelsfrom before to after the health education program. However, fasting glucose levels (overall $\mathrm{t}=$ $2.5, \mathrm{p}<0.05$,female $\mathrm{t}=2.5$ ) and HbA1c levels (overall $\mathrm{t}=4.6$, male $\mathrm{t}=2.8$, female $\mathrm{t}=3.8$ ) were significantly increased after the health education program.

\section{Table V: Blood chemistry before and after the CT and CA health education programs}

\begin{tabular}{|c|c|c|c|c|c|c|c|}
\hline \multirow[b]{2}{*}{ Blood chemistry } & \multirow[b]{2}{*}{ Sex } & \multicolumn{2}{|c|}{ CA } & \multicolumn{4}{|c|}{ CT } \\
\hline & & Before & After & $\mathrm{p}$-value & Before & After & p-value \\
\hline \multirow[t]{3}{*}{ HDL (mg/dl) } & male and female & $74.0 \pm 2.1$ & $74.8 \pm 2.3$ & NS & $61.0 \pm 2.2$ & $61.1 \pm 2.0$ & NS \\
\hline & male & $66.8 \pm 3.1$ & $67.3 \pm 3.4$ & NS & $54.2 \pm 2.7$ & $55.1 \pm 3.0$ & NS \\
\hline & female & $77.8 \pm 2.7$ & $78.6 \pm 2.9$ & NS & $66.4 \pm 3.0$ & $65.9 \pm 2.4$ & NS \\
\hline \multirow[t]{3}{*}{ LDL (mg/dl) } & male and female & $130.8 \pm 3.6$ & $129.7 \pm 2.8$ & NS & $127.2 \pm 4.1$ & $127.6 \pm 4.2$ & NS \\
\hline & male & $119.5 \pm 5.0$ & $125.3 \pm 4.8$ & NS & $132.0 \pm 5.8$ & $131.5 \pm 6.3$ & NS \\
\hline & female & $136.6 \pm 4.6$ & $132.0 \pm 3.5$ & NS & $123.5 \pm 5.7$ & $124.5 \pm 5.7$ & NS \\
\hline \multirow[t]{3}{*}{ Triglyceride (mg/dl) } & male and female & $100.9 \pm 4.6$ & $102.9 \pm 5.4$ & NS & $118.2 \pm 9.1$ & $114.9 \pm 9.4$ & NS \\
\hline & male & $103.8 \pm 7.5$ & $112.8 \pm 10.7$ & NS & $139.2 \pm 14.6$ & $138.3 \pm 17.0$ & NS \\
\hline & female & $99.4 \pm 5.8$ & $97.7 \pm 6.0$ & NS & $101.6 \pm 10.6$ & $96.4 \pm 8.9$ & NS \\
\hline \multirow[t]{3}{*}{ Fasting glucose (mg/dl) } & male and female & $102.0 \pm 1.7$ & $105.3 \pm 2.0$ & $<0.001$ & $103.1 \pm 2.7$ & $100.0 \pm 2.2$ & $<0.05$ \\
\hline & male & $107.6 \pm 3.7$ & $111.8 \pm 4.9$ & $<0.05$ & $107.3 \pm 4.7$ & $104.3 \pm 3.5$ & NS \\
\hline & female & $99.1 \pm 1.6$ & $101.8 \pm 1.6$ & $<0.05$ & $99.8 \pm 3.1$ & $96.7 \pm 2.8$ & $<0.05$ \\
\hline \multirow[t]{3}{*}{$\mathrm{HbA1c}(\mathrm{mg} / \mathrm{dl})$} & male and female & $5.3 \pm 0.1$ & $5.5 \pm 0.1$ & $<0.001$ & $5.5 \pm 0.1$ & $5.3 \pm 0.1$ & $<0.001$ \\
\hline & male & $5.5 \pm 0.2$ & $5.6 \pm 0.2$ & $<0.01$ & $5.5 \pm 0.1$ & $5.3 \pm 0.1$ & $<0.05$ \\
\hline & female & $5.3 \pm 0.0$ & $5.4 \pm 0.1$ & $<0.001$ & $5.5 \pm 0.1$ & $5.3 \pm 0.1$ & $<0.001$ \\
\hline
\end{tabular}

Data are presented as mean \pm SE. NS: not significant; HbA1C: glycosylated hemoglobin; LDL: low-density lipoprotein cholesterol; HDL: high-density lipoprotein cholesterol; CA group: monthly classroom activity only, the Matsumoto city cohort; CT group: the classroom/training (CT) group, monthly classroom activity plus weekly 90-min strength and weight training, the Minowa town cohort

\section{Go/no-go tasks of the brain function test}

Table VI summarizes the response times (in ms) for the go/no-go task, whereas Table VII summarizes the number of errors (forget or mistake). The males and females of the CA groupshowed no significant differences in response times for the differentiation task, the reverse differentiation task, total response times, number of forgets for the differentiation task, number of mistakes for the differentiation task, number of forgets for the reverse differentiation task, number of mistakes for the reverse differentiation task, or total number of forgets and mistakes before and after the health education program.However, they showedsignificant differences in response times for the formation task (overall $t=-2.5$, femalet $=-2.3$ ) from before to after the health education program. In contrast, the CT groupshowed no significant differences in response times for the formation task, response times for the reverse differentiation task, number of forgets for the differentiation task, number of forgets for the reverse differentiation task, number of mistakes for the 
Watanbe et.al/Differences Between Two Japanese Health-Promotion Programs On Measures Of Health And Wellness

reverse differentiation task, or total number of forgets and mistakes from before to after the health education program. However, they showedsignificant differences in response times for the differentiation task (overall $t=2.1$, malet $=2.8$ ), total response times (overall $t=2.4$, male $t=3.2$ ), and number of mistakes for the differentiation task (overall $t=4.2$, ale $t=3.8$, femalet $=2.2$ ) from before to after the health education program.

Table VI: Response time for the go/no-go task before and after the CT and CA health education programs

\begin{tabular}{|c|c|c|c|c|c|c|c|}
\hline \multirow[b]{2}{*}{ Response time of go/no-go task(ms) } & \multirow[b]{2}{*}{ Sex } & \multicolumn{2}{|c|}{ CA } & \multicolumn{4}{|c|}{ CT } \\
\hline & & Before & After & $\mathrm{p}$-value & Before & After & $\mathrm{p}$-value \\
\hline \multirow[t]{3}{*}{ Response time of formation } & male and female & $242.0 \pm 5.8$ & $257.3 \pm 5.7$ & $<0.05$ & $258.0 \pm 8.2$ & $243.1 \pm 5.5$ & NS \\
\hline & male & $233.9 \pm 10.1$ & $245.7 \pm 9.7$ & NS & $246.3 \pm 8.3$ & $226.5 \pm 6.9$ & NS \\
\hline & female & $245.8 \pm 7.0$ & $262.8 \pm 7.0$ & $<0.05$ & $269.7 \pm 14.0$ & $259.8 \pm 6.9$ & NS \\
\hline \multirow[t]{3}{*}{ Response time of differentiation } & male and female & $367.6 \pm 8.0$ & $373.0 \pm 7.4$ & NS & $403.0 \pm 8.5$ & $381.0 \pm 9.3$ & $<0.05$ \\
\hline & male & $354.8 \pm 13.4$ & $363.5 \pm 10.9$ & NS & $398.8 \pm 11.8$ & $362.5 \pm 12.5$ & $<0.05$ \\
\hline & female & $373.7 \pm 9.9$ & $377.6 \pm 9.6$ & NS & $407.2 \pm 12.5$ & $399.6 \pm 12.7$ & NS \\
\hline \multirow[t]{3}{*}{ Response time of reverse differentiation } & male and female & $387.3 \pm 7.1$ & $393.4 \pm 7.7$ & NS & $428.8 \pm 10.3$ & $412.8 \pm 10.9$ & NS \\
\hline & male & $369.0 \pm 13.5$ & $372.8 \pm 11.7$ & NS & $417.7 \pm 12.5$ & $392.1 \pm 15.1$ & NS \\
\hline & female & $396.0 \pm 8.1$ & $403.1 \pm 9.6$ & NS & $439.9 \pm 16.2$ & $433.4 \pm 14.7$ & NS \\
\hline \multirow[t]{3}{*}{ Response time of total } & male and female & $352.7 \pm 6.3$ & $359.8 \pm 6.3$ & NS & $386.9 \pm 7.5$ & $367.6 \pm 8.2$ & $<0.05$ \\
\hline & male & $338.1 \pm 11.0$ & $345.4 \pm 9.5$ & NS & $378.5 \pm 9.7$ & $347.4 \pm 10.6$ & $<0.01$ \\
\hline & female & $59.6 \pm 7.5$ & $366.6 \pm 7.9$ & NS & $395.2 \pm 11.3$ & $387.7 \pm 11.0$ & NS \\
\hline
\end{tabular}

Data are presented as mean \pm SE. NS: not significant; CA group: monthly classroom activity only, the Matsumoto city cohort; CT group: the classroom/training (CT) group, monthly classroom activity plus weekly 90-min strength and weight training, the Minowa town cohort

Table VII: The number of error of go/no-go task before and after health education in CTG and CG

CA

\begin{tabular}{|c|c|c|c|c|c|c|c|}
\hline Number of errors (times) & Sex & Before & After & $\mathrm{p}$-value & Before & After & p-value \\
\hline \multirow[t]{3}{*}{ Forget of the differentiation } & male and female & $0.1 \pm 0.0$ & $0.0 \pm 0.0$ & NS & $0.0 \pm 0.0$ & $0.1 \pm 0.1$ & NS \\
\hline & male & $0.1 \pm 0.1$ & $0.0 \pm 0.0$ & NS & $0.0 \pm 0.0$ & $0.1 \pm 0.1$ & NS \\
\hline & female & $0.0 \pm 0.0$ & $0.0 \pm 0.0$ & NS & $0.1 \pm 0.1$ & $0.0 \pm 0.0$ & NS \\
\hline \multirow[t]{3}{*}{ Mistake of differentiation } & male and female & $2.9 \pm 0.3$ & $2.8 \pm 0.3$ & NS & $2.1 \pm 0.3$ & $1.3 \pm 0.2$ & $<0.001$ \\
\hline & male & $2.9 \pm 0.4$ & $2.3 \pm 0.4$ & NS & $2.5 \pm 0.4$ & $1.5 \pm 0.3$ & $<0.01$ \\
\hline & female & $2.9 \pm 0.3$ & $3.1 \pm 0.4$ & NS & $1.8 \pm 0.4$ & $1.1 \pm 0.3$ & $<0.05$ \\
\hline \multirow[t]{3}{*}{ Forget of reverse differentiation } & male and female & $0.1 \pm 0.1$ & $0.1 \pm 0.0$ & NS & $0.1 \pm 0.0$ & $0.2 \pm 0.2$ & NS \\
\hline & male & $0.2 \pm 0.2$ & $0.1 \pm 0.1$ & NS & $0.1 \pm 0.1$ & $0.4 \pm 0.4$ & NS \\
\hline & female & $0.1 \pm 0.0$ & $0.1 \pm 0.0$ & NS & $0.1 \pm 0.1$ & $0.0 \pm 0.0$ & NS \\
\hline \multirow[t]{3}{*}{ Mistake of reverse differentiation } & male and female & $2.9 \pm 0.3$ & $2.8 \pm 0.3$ & NS & $0.9 \pm 0.2$ & $0.6 \pm 0.1$ & NS \\
\hline & male & $2.9 \pm 0.4$ & $2.3 \pm 0.4$ & NS & $1.0 \pm 0.2$ & $0.9 \pm 0.3$ & NS \\
\hline & female & $2.9 \pm 0.3$ & $3.1 \pm 0.4$ & NS & $0.7 \pm 0.2$ & $0.3 \pm 0.1$ & NS \\
\hline \multirow[t]{2}{*}{ Total of forget } & male and female & $0.2 \pm 0.1$ & $0.1 \pm 0.0$ & NS & $0.1 \pm 0.0$ & $0.2 \pm 0.2$ & NS \\
\hline & male & $0.3 \pm 0.2$ & $0.1 \pm 0.1$ & NS & $0.1 \pm 0.1$ & $0.5 \pm 0.5$ & NS \\
\hline
\end{tabular}


Watanbe et.al/Differences Between Two Japanese Health-Promotion Programs On Measures Of Health And Wellness

\begin{tabular}{llllllll}
\hline & female & $0.1 \pm 0.0$ & $0.1 \pm 0.0$ & NS & $0.1 \pm 0.1$ & $0.0 \pm 0.0$ & NS \\
\hline Total of mistake & male and female & $4.7 \pm 0.5$ & $4.4 \pm 0.5$ & NS & $3.0 \pm 0.4$ & $1.9 \pm 0.3$ & $<0.001$ \\
\hline & male & $4.7 \pm 0.7$ & $3.9 \pm 0.8$ & NS & $3.5 \pm 0.5$ & $2.4 \pm 0.5$ & $<0.01$ \\
\hline fotal of forget and mistake & female & $4.7 \pm 0.6$ & $4.7 \pm 0.6$ & NS & $2.5 \pm 0.6$ & $1.4 \pm 0.4$ & $<0.05$ \\
\hline & male and female & $4.8 \pm 0.5$ & $4.5 \pm 0.5$ & NS & $3.1 \pm 0.4$ & $2.1 \pm 0.4$ & $<0.05$ \\
\hline & male & $5.1 \pm 0.7$ & $4.0 \pm 0.7$ & NS & $3.5 \pm 06$ & $2.8 \pm 0.7$ & NS \\
\hline & female & $4.8 \pm 0.6$ & $4.7 \pm 0.6$ & NS & $2.6 \pm 0.6$ & $1.4 \pm 0.4$ & $<0.05$ \\
\hline
\end{tabular}

Data are presented as mean \pm SE. NS: not significant.

The repeated two-way ANOVA results of the health education program for theCA and CT groups' before and after itemsshowed no significant differences.

\section{DISCUSSION}

\section{Walking steps of the pedometer}

The daily average walking steps in the CT groupwas 8687 compared with 7242 in the CA group, i.e., approximately 1,400 steps more. In the CA group, although the average amount of walking and exercise steps gradually increased from May to September, the number of walking steps decreased from September to February. A similar pattern was seen in the average amount of walking and exercise steps from May to October in the CT group, but both walking and exercise steps decreased from October to February. Minowatown (CT group) is approximately 50 km from the city of Matsumoto(CA group), and both areas have the same climate, with thetemperaturefalling from October toan average winter temperature of approximately-6.6 ${ }^{\circ} \mathrm{C}$. The numbers of walking steps began to decrease from October in the CA groupand from December in the CT group under comparable climates, suggesting that the CT group may have more health awareness. In addition,malesin both groups may have stronger health awareness than femalesin both groups because males performed more daily steps compared withfemales.

Paffenbargheret al. reported that expending more than $2000 \mathrm{kcal} /$ week reduced the risk of heart attacks [17]. In addition, walking 10,000 steps/day improves glucose tolerance and reduces blood pressure, both of which are risk factors for type 2 diabetes [18,19]. However, participants of previous health education programs complained of knee and low back pain because of excessive walking [13]; hence, we measured the WBI and set individualized walking targets.

\section{Anthropometry and blood pressure}

The CA group showed significant decreases in weight and waist circumference from before to after the health education program. Although maleslost more weight than females did, males had smaller decreases in waist circumference. In the CA group, there were also no significant differences in either BMI or blood pressure from before to after the health education program. In contrast, the CT group showed significant decreases in weight, BMI, waist circumference, systolic blood pressure, and diastolic blood pressure from before to after the health education program. However, malesshowed no significant difference in weight or BMI from before to after the CT health education program. When comparing the CT andCA groups, the former showed the most significant improvement from before to after the program.Aerobic exercise and health education to walk more can help decrease weight, BMI, and blood pressure [20,21]. In our study, the CT groupshowed a significant improvement in the BMI and blood pressure compared with the CA group. This may have been because the CT groupwalked an average of 1,400 steps more than the CA group and performed 90-minweight training once a week.

\section{Physical fitness test}

From before to after the health education programs, the CA group showed significant improvements in sit-ups, sit-and-reach flexibility, eyes-open single-leg stance, 10-m obstacle walk, and 6-min walk, whereas the CT group showed significant improvements in handgrip strength, sit-ups, sit-and-reach flexibility, 10-m obstacle walk, and 6-min walk.Although the CA group showed significant overall improvements in sit-ups and sit-and-reach flexibility after the health education program, femalesshowed no significant improvement in the sit-up domain (muscular endurance) and males showed no significant improvement in the sit-and-reach flexibility domain. This result may suggest that it is easier to improve muscular endurance in males, while 
flexibility is easier to improve in female.

The CT and CA groups showed no significant improvements in eyes-open single-leg stance and handgrip strength, respectively. However, the eyes-open single-leg stance in the CT group was almost $120 \mathrm{~s}$ of the maximum and was higher than in the CA group. Muscular strength isnot known to improve when exercising by only walking [22]. Therefore, handgrip strength may have decreased in the CA group after receiving health education only. The CT group showed a more significant improvement from before to after the health education program.

\section{Blood chemistry}

From before to after the health education program, the CA group showed significant increases in fasting glucose and HbA1c levels, whereas the CT group showed significant decreases in fasting glucose and HbA1c levels. This is consistent with evidence that HbA1c and fasting glucose significantly decreased in patients with diabetes who participated in aerobic and resistance exercise programs [23, 24]. The afore mentioned differences in HbA1c and fasting glucose levels may have been due to the greater amount of walking and theweekly 90-min weight training in the CT group.

\section{Go/no-go tasks of the brain function test}

Although the go/no-go task was initially developed to investigate brain function in children [25], it has been reported to be suitable for brain function screening indementia [26]. A previous go/no-go task study suggested that a health program could improve brain function, including working memory[27]. In that study, participants performed an average of 6,500 steps/day in the first year of continuous exercise, at the end of which their go/no-go task reaction times increased significantly andthe number of error responses decreased significantly. In the secondyear, the walking exercise was continued at an average of 7,000 steps/day anda 2-h weight-training session was introduced. This led to further reductions in the reaction times and the number of error responses. In our study, the males andfemales in the CA groupshowed significant delays in response times for the formation task. In contrast, the CT group showed significantly faster response times for the differentiation task and the total response time. Furthermore, the CT group showed significant decreases in the number of mistakes during the differentiation and reverse differentiation tasks.

\section{CONCLUSION}

We implemented two 10-month health education programs that compared classroom activity alone (i.e., the CA program) with classroom activity plus weekly 90-min strength and weight training (i.e., the CT program). Overall, the CT program appeared to be more effective than the CA program on the measures tested. The CT group: walked more (energy expenditure); had greater improvements in BMI and blood pressure (anthropometric measures); showedsignificant improvements in handgrip strength, sit-ups, sit-and-reach flexibility, 10-m obstacle walk, and 6-min walk (physical fitness); showed decreasedHbA1c and fasting glucose (blood measures); and, in the go/no-go tasks, faster overall and differentiation response times, and significantly fewer mistakes in the differentiation and reverse differentiation elements (brain function). However, the CA group did show significant improvement in sit-ups, sit-and-reach flexibility, eyes-open single-leg stance, 10-m obstacle walk, and 6-min walk (physical fitness). Notably, the CA group also showed significant increases in both HbA1c and fasting glucose, as well as significant delays in the response times for the formation task (go/no-go task). Thus, the CT programwas superior to the CA program on the measures used.In conclusion, the CT program had added benefits over the CA program because of the higher average amount of walking (approximately 1,400 steps) and the inclusion of a weekly weight-training activity.

\section{ACKNOWLEDGMENTS}

This study was supported by a grant of the Preventive Medical Center of Shinshu University Hospital from Ministry of Education, Culture, Science and Technology. In addition, Koji Terasawa was supported by a Grant-in-Aid for the Scientist (Houga: 23650426, KibanA: 25257101) provided by the Ministry of Education, Culture, Sports, Science and Technology of Japan.

\section{REFERENCES}

[1] Kickbush D. (1986) Health promotion, a global perspective.Can. J. Public Health 77: 321-7.

[2] Japan Health Promotion \& Foundation. (2000) http://www.kenkounippon21.gr.jp/.

[3] Ministry of Health, Labour and Welfare.http://www.mhlw.go.jp/bunya/kenkou/seikatsu/. 
[4] Alberti KG, Zimmet PZ. (1998) Definition, diagnosis and classification of diabetes mellitus and its complications. Part 1: diagnosis and classification of diabetes mellitus provisional report of a WHO consultation. Diabetes Med. 15:539-53.

[5] Sabia S1, Elbaz A, Rouveau N, Brunner EJ, Kivimaki M, Singh-Manoux A. (2014) Cumulative associations between midlife health behaviors and physical functioning in early old age: a 17-year prospective cohort study. J. Am.Geriatr. Soc.62:1860-8.

[6] Mora-Rodriguez R, Ortega JF, Hamouti N, Fernandez-Elias VE, Cañete Garcia-Prieto J, Guadalupe-Grau A, et al. (2014) Time-course effects of aerobic interval training and detraining in patients with metabolic syndrome. Nutr.Metab.Cardiovasc. Dis.24:792-8.

[7] Abreu EL, Cheng AL, Kelly PJ, Chertoff K, Brotto L, Griffith E, et al.(2014) Skeletal muscle troponin as a novel biomarker to enhance assessment of the impact of strength training on fall prevention in the older adults. Nurs. Res.63:75-82.

[8] Andersen TR, Schmidt JF, Nielsen JJ, Randers MB, Sundstrup E, Jakobsen MD, et al. (2014) Effect of football or strength training on functional ability and physical performance in untrained old men. Scand. J. Med. Sci. Sports 1:76-85.

[9] Sakai A, Terasawa K, Inaki M, Yangidaira Y, Kobayashi I, Oana S, et al. (2000) Physical effects of "The Matsumoto physical training program for senior citizens."ShinshuMed. J.48: 89-96.

[10] Terasawa K, Nakajima K, Zhang Y, Hirota N, Kobayashi T, Ishii M, et al. (2006) Nagano Wellness University Asia Pacific Project for Maintaining Health in Aging. 3 rd Active Aging in Asia Pacific.

[11] Teraswa K, Nakade K, Okuhara M, Nakajima K, Fujimori S, Miura H, et al. (2008) A study of the relationship between muscle quantity and balance and brain function. J. Aging Phys. Act. 16: s176.

[12] Kikawa A., Yamamoto T.(1991) The functional muscular strength measurement. Rating system of Weight Bearing Index. The Japanese Orthopaedic Society for Sports Medicine, 10:463-468.

[13] Yamamoto T, Muranaga S. (2002) Easy law of the lower limbs muscular strength by the evaluation of the ability to stand up. Sports Med.41: 38-40.

[14] Ministry of Education, Culture, Sports, Science and Technology. http://www.mext.go.jp/.

[15] Ministry of Health, Labor and Welfare.http://www.mhlw.go.jp/bunya/kenkou/seikatsu/.

[16] Masaki T, Moriyama G. (1971) Study on types of human higher nervous activity. Tokyo University of Science Press. 4: 69-81(in Japanese).

[17] Paffenbarger RS, Jr, Wing AL, Hyde RT. (1978) Physical activity as anindex of heart attack risk in college alumni. Am. J.Epidemiol. 108: 161-75.

[18] Moreau KL, Degarmo R, Langley J,McMahon C, Howley ET, Bassett DR, Jr, et al. (2001) Increasing daily walking lowers blood pressure in postmenopausal women with borderline to stage I hypertension. Med. Sci. Sports Exerc.33: 1825-31.

[19] Swartz AM, Strath SJ, Bassett DR, Moore JB, Redwine BA, Groër M, et al. (2003) Increasing daily walking improves glucose tolerance in overweight women. Prev. Med.37: 356-62.

[20] Park JH, Miyashita M, Takahashi M, Kawanishi N, Hayashida H, Kim HS, et al. (2014) Low-volume walking program improves cardiovascular-related health in older adults. J. Sports Sci. Med.13:624-31.

[21] Ryan AS, Katzel LI, Prior SJ, McLenithan JC, Goldberg AP, Ortmeyer HK. (2014) Aerobic exercise plus weight loss improves insulin sensitivity and increases skeletal muscle glycogen synthase activity in older men. J.Gerontol. A. Biol. Sci. Med. Sci.69:790-8.

[22] Virág A, Karóczi CK, Jakab A, Vass Z, Kovács E, Gondos T. (2014) Short-term and long-term effects of Nordic Walking training on balance, functional mobility, muscle strength and aerobic endurance among Hungarian community-living older people: a feasibility study. J. Sports Med. Phys. Fitness.

[23] Yardley JE, Hay J, Abou-Setta AM, Marks SD, McGavock J. (2014) A systematic review and meta-analysis of exercise interventions in adults with type 1 diabetes. Diabetes Res ClinPract.106:393-400.

[24] Lynch EB, Liebman R, Ventrelle J, Keim K, Appelhans BM, Avery EF, et al. (2014) Design of the Lifestyle Improvement through Food and Exercise (LIFE) study: a randomized controlled trial of self-management of type 2 diabetes among African American patients from safety net health centers. Contemp.Clin. Trials 39:246-55. 
[25] Terasawa K, Tabuchi H, Yanagisawa H, Yanagisawa A, Shinohara K, Terasawa S, et al. (2014) Comparative survey of go/no-go results to identify the inhibitory control ability change of Japanese children. BioPsychoSocialMed.8: 1-7.

[26] Terasawa K, Misaki S, Murata Y, Watanabe T, Terasawa S, Kobayashi T, et al. (2014) Relevance between Alzheimer's disease patients and normal subjects using go/no-go tasks and Alzheimer assessment scores. J. Child Adolesc. Behav.2: 162.

[27] Murata Y, Nemoto K, Kobayashi I, Ippongi Y, Terasawa S, Osawa S, et al. (2013)The effect of two-year health program on the Go/No-Go, physical fitness, and blood test. 21st IUHPE World Conference on Health Promotion.

How to cite this article: Watanabe, Toshiaki. differences between two japanese health-promotion programs on measures of health and wellness. Innovative Journal of Medical and Health Science, [S.l.], v. 5, n. 4, p. 170-181, aug. 2015. ISSN 2277-4939. Available at: <http://innovativejournal.in/ijmhs/index.php/ijmhs/article/view/75>. Date accessed: 02 Sep. 2015. doi:10.15520/ijmhs.2015.vol5.iss4.75.170-181. 